

\title{
View of the Future and Making Big Bets: The Missing Piece of the "Puzzle" of Healthcare Innovation?
}

\author{
Umair Majid $^{1}$ \\ ${ }^{1}$ Institute of Health Policy, Management, and Evaluation, University of Toronto
}

The rising costs of healthcare has increased pressures to develop innovations and interventions to complete the "puzzle" of healthcare (e.g., The Triple Aim - outcomes, cost-effectiveness, and experience). However, the majority of efforts miss many pieces of this puzzle. One important piece is viewing the "big picture"; the forest for trees; the healthcare system from a 30,000-foot view.

Seeing the big picture does not only involve understanding the current structure and function of the healthcare system, but how the industry may evolve as a result of market forces, innovations, and discoveries [1]. This thinking has been applied in some areas of healthcare, for example the scholarship of implementation science and management. However, this idea remains elusive in the practice of health administration, innovation, and quality improvement. The objective of this article is to discuss why a "view of the future" is essential for healthcare improvement and how practitioners working in this area may incorporate this thinking in practice.

\section{VIEW OF THE FUTURE}

The view of the future originates from a belief that health systems are complex and constantly changing [2]. Without acknowledging and embedding these characteristics into the design of innovations and interventions, a health system may produce services and processes that are ineffective, inappropriate, and inefficient to patients and family. For example, if a health service organization does not envision how an emerging technology may shift the structure and functioning of the industry, then products or services are at-risk of becoming obsolete as individuals' behaviors, interactions, and lifestyles become more aligned with the new technology, and the products and services become misaligned with the intended population.

Viewing the future has broad implications for innovations and interventions. However, few organizations in healthcare spend sufficient time on this exercise. In 1994, Hamel and Prahalad described the $\mathbf{4 0 / 3 0 / 2 0}$ rule: $40 \%$ of an executive's total time is devoted to looking outward; $30 \%$ of this time is dedicated to looking at three, four, five or more years in the future $(0.30 \times 40 \%=12 \%$ of total time $)$; and $20 \%$ of this time is dedicated to building a view of the future $(0.20 \times 12 \%=2.4 \%$ of total time $)$ and $80 \%$ on the current business model [3]. In other words, approximately only $2.4 \%$ of an executive's total time is devoted to building a view of the future [3]. This observation is a major gap in healthcare innovation, as well as an opportunity to improve the responsiveness and sustainability of health services.

Engaging in the view of the future is an uncomfortable exercise for healthcare professionals because it brings forward the possibility that health services may become obsolete, irrelevant, or ineffective in the future. However, the uncertainty inherent in viewing the future is also an opportunity. Using collective understanding of the healthcare industry and market forces may enable health service organizations to evolve their services to be more aligned with the needs, preferences, and perspectives of patients and family. One example of an opportunity observed today is many individuals are choosing to age at home instead of at institutions [4]. However, the infrastructure for aging at home has not met the demand or need for these services, possibly reflecting how systems have not viewed their structure and function in the future [5].

\section{View of Future Exercise}

The view of the future is an exercise developed by Tan and colleagues (2015) in their book: Tao of Innovation: Nine Questions Every Innovator Must Answer. They offer two steps to completing this exercise [6]. The first step is to construct the view of the future, which includes spotting changes in the industry that may dramatically shift its structure and function. A healthcare example of a dramatic shift includes the implications of machine learning for research, planning and designing, service delivery, and quality improvement. Constructing a view of the future requires healthcare professionals to engage in a dialogue that considers technology, people, climate, environment, market, policy, economics, ethics, systems, and industrial forces. Tan and colleagues (2015) recommend answering seven questions shown below [6]. 
1. What are customers' priorities today and how will they change in the future?

2. Which customers do I serve today and how will they change in the future?

3. What channels do I use to reach them today and which ones will I use down the road?

4. Who are my competitors today and who will they be in the future?

5. What is the basis for my competitive advantage today and what will it be in the future?

6. Where do my margins come from today and where will they come from in the future?

7. What are our core competencies today and what new capabilities and core competencies do we need to develop to compete in the future?

The second step is to lay new bets, which requires identifying "big bets" that a health service organization is willing to make that will fundamentally change how it functions within the broader system. Laying new bets follows the 80/20 metaphor - a process or service that contributes $20 \%$ of value today will contribute to $80 \%$ in the future [7]. For example, there has been a gradual shift from institutional to community care in the last few decades. Healthcare institutions (e.g., large hospitals) emerged from postWW2 efforts to meet the demands for acute care. However, the increasing expectancy and longevity of populations engendered a strong need for infrastructure for citizens to access health services in community facilities. In the middle of the 20th century, community care may have contributed to $20 \%$ of need, but with time, it will contribute to $80 \%$ of value in some jurisdictions. Using this metaphor adapts health systems to broader changes in behaviors, interactions, and lifestyles.

\section{Conclusion}

In future health systems, stakeholders will need to exemplify an increased capacity for open-mindedness, resiliency, and collaboration. Foresight and adaptation are essential principles to achieve a view of the future and build a system that is more sustainable and aligned with patient needs and preferences. This article discussed the importance of viewing the future of health systems and provided a list of questions from Tan and colleagues (2015) for practitioners to create a view of the future and contribute to a more sustainable health system. However, it is difficult to evaluate the impact of viewing the future and related exercises. Future research should look how health service organizations who dedicate time to building a view of the future differ from those who do not.

\section{REFERENCES}

[1] Agarwal R, Gort M. The evolution of markets and entry, exit and survival of firms. The review of Economics and Statistics. 1996;p. 489-498.

[2] Greenhalgh T, Papoutsi C. Studying complexity in health services research: desperately seeking an overdue paradigm shift. BioMed Central; 2018.

[3] Prahalad CK, Hamel G. Competing for the Future. vol. 25. Harvard Business School Press Boston; 1994.

[4] Coyte PC, McKeever P. Home care in Canada: Passing the buck. Canadian Journal of Nursing Research Archive. 2016;33(2).

[5] Williams AP, Lum J, Deber R, Montgomery R, Kuluski K, Peckham A, et al. Aging at home: integrating community-based care for older persons. Healthcare Papers. $2009 ; 10(1): 8-21$.

[6] Tan TK, Seow H, Toyofuku ST, et al. The tao of innovation: Nine questions every innovator must answer. Imperical College Press; 2015.

[7] Nisonger TE. The " $80 / 20$ rule" and core journals. The Serials Librarian. 2008;55(1-2):62-84.

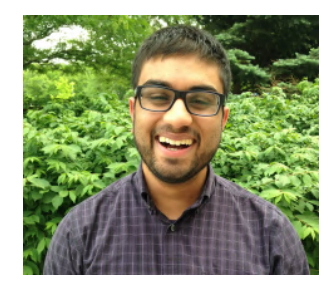

Umair Majid has a MSc in Health Research Methodology from McMaster University and MEd in Curricula Design from Queen's University. Currently, Umair is a Research Associate at University Health Network and $\mathrm{PhD}$ student in Health Services Management and Organization at University of Toronto. For his dissertation, Umair is investigating how to improve the mechanisms of patient engagement in hospital planning activities. 